\title{
Effects of Pre-reading Activities on EFL Reading by Iranian College Students
}

\author{
Mohammad Reza Salehi*, Ebrahim Abbaszadeh
}

Khatam - AL - Anbia University, Iran

Copyright $\bigcirc 2017$ by authors, all rights reserved. Authors agree that this article remains permanently open access under the terms of the Creative Commons Attribution License 4.0 International License

\begin{abstract}
This study investigated the effects of two pre-reading activities (class discussion and vocabulary definitions) and a control condition on the reading comprehension of 57 Iranian college freshmen. It also investigated the differential facilitative effect of the two pre-reading activities on the students' comprehension. Each student read an expository text under one of the three conditions and immediately afterwards answered a 9-item short answer test designed to measure comprehension of the text. A one-way ANOVA and a post-hoc comparison test were applied to the results. This revealed that the two pre-reading activities produced significantly higher comprehension scores than the control condition. Vocabulary definitions activity resulted in increased comprehension compared with the control condition, but was significantly less effective than the class discussion activity. Results of the study were interpreted in relation to the schema-theoretic view of the reading process, and to their implications for EFL reading instruction.
\end{abstract}

Keywords Pre-reading Activities, Activating Background Knowledge, Reading Comprehension

\section{Research Background}

EFL students tend to experience considerable difficulty in understanding English texts. Not only do these texts most often contain unfamiliar vocabulary, but they also may contain unfamiliar concepts and cultural content that make comprehension difficult. Traditionally, attempts to enhance text comprehension for EFL students have focused on familiarizing the students with the vocabulary needed to comprehend the passage (Bernhardt, 1984). [4] Such instruction, however, is unlikely to raise students' interest in reading the text or to well prepare them for the conceptually and culturally novel elements of the text. A large body of research within the schema-theoretic view of reading comprehension has acknowledged the active role of background knowledge and the extent to which that knowledge is activated during the reading process (Anderson \& Pearson, 1984; Carrell 1983, Carrell\& Wallace, 1983; Rumelhart, 1980). [1] Accordingly, efficient comprehension requires readers to relate the material to their background knowledge. Therefore, Building or activating background knowledge prior to reading ought to produce better reading comprehension. Thus, several studies have been conducted to investigate the effects of pre-reading activities as a means of providing and triggering off background information prior to the reading task (Graves \& Chen, 1995; Graves \& Cooke, 1980, Graves et al., 1983; Hudson, 1982; Johnson, 1981, 1982; Langer, 1984; Maghsoudi, 2012; Stevens, 1982; Taglieber et al., 1988) [17]. These studies suggest that pre-reading activities have a facilitative effect in text comprehension, and that teachers can use them to provide and/or activate necessary background knowledge relevant to understanding the new text. Pre-reading activities are intended to activate appropriate knowledge structures or provide the knowledge that the reader lacks. "Pre-reading activities prepare native speakers for the concepts that follow, make the reading task easier, connect the new content more meaningfully to prior knowledge, and make reading more enjoyable" (Taglieber et al., 1988, p. 456). [35] EFLreaders' comprehension is dependent on their schemata as well (Carrell \& Eisterhold, 1983). When reading texts that are loaded with highly unfamiliar content, comprehension will be difficult, if not impossible, because of the readers' lack of appropriate background knowledge (Taglieber et al., 1988). [35] Two seemingly most practical pre-reading techniques for EFL learners were examined in this study. Vocabulary definitions technique has been shown to improve comprehension of L2 speakers of English under some circumstances (Carlo et al., 2004; Hudson, 1982; Taglieber, Johnson \& Yarbrough, 1988).[6] The class discussion technique has earned some research support within the schema-theoretic view of reading for both native and nonnative speakers (Carrell, 1984; Gebhard, 1987; Hudson, 1982, Langer, 1984). [21] Langer (1984) [15] examined in a single study the effects of three pre-reading activities (a discussion of key concepts (PReP), a general discussion of the topic, and a non-topic related discussion) and a control condition on L1 readers' comprehension of texts. It was found 
that a discussion of the text related topic and the PReP was significantly more effective for reading comprehension than the control condition. However, no study has made a direct comparison between vocabulary definitions and class discussion pre-reading activity. In an ESL context, Carlo et al. (2004) found that intensive rich vocabulary instruction that involved meeting target words in multiple contexts had a significant effect on fifth-grade ESL learners' scores on a cloze test designed to measure comprehension. In another study, Hudson (1982) [21] examined the effect of three different pre-reading activities on reading comprehension of ESL students at various language proficiency levels. He found that picture prediction (PRE), Read-Test/Read-Test (RT), and presentation of vocabulary items (VOC) prior to reading seemed to greatly, though differentially, facilitate students comprehension at all levels. However, in closely examining his data, Hudson argued that the pre-reading effect was relative to the students' level of English. While VOC and RT treatment were less effective than the PRE treatment at the beginning and intermediate levels, they were as or more effective at the advanced level. In an EFL context, different results were obtained as to the effects of vocabulary instruction on students reading comprehension. Johnson (1982) [22] investigated two aspects of background knowledge: prior cultural experience and vocabulary range. A sample of 72 advanced ESL students from 23 countries read a passage on the celebration of Halloween. The passage contained unfamiliar and familiar information based on the subjects' recent experience of this custom. Prior to reading, the subjects were presented with a pre-selected list of vocabulary definitions to be found in the reading passage. The results indicated that prior cultural experience had a positive effect on the subjects' comprehension of the familiar information about Halloween in the passage. However, exposure to the target words definitions seemed not to have a recognizable influence on the subjects' reading comprehension. This implies that teaching relevant schema promotes the comprehension of cultural material more than vocabulary pre-teaching. In fact, general topic knowledge, not just culturally bound prior knowledge, is also significant in EFL reading comprehension (Hammadou, 1991; Hudson, 1982). [20] Tagliber, Johnson and Yarbough (1988) [20] investigated the effects of three pre-reading activities (pictorial context, vocabulary pre-teaching and pre-questioning) and a control condition on the reading comprehension of 40 undergraduate Brazilian EFL students. The results indicated that vocabulary pre-teaching resulted in increased comprehension compared with the control but was significantly less effective than the other two strategies. These findings suggest that pre-reading activities also facilitate EFL students comprehension and with varying degrees of success. In another study, Webb (2009) [36] investigated the effects of pre-learning vocabulary on reading comprehension and writing of Japanese EFL learners. Specifically, the study was designed to investigate the effects of receptive and productive learning of word pairs. The findings suggest that pre-learning FL vocabulary may be an effective method of improving reading comprehension and writing, depending on the method of instruction. Receptive vocabulary learning may lead to greater understanding of sentences, while productive learning may lead to greater success in using taught words in writing. In a more recent study, Maghsoudi (2012) [26] investigated the effects of schema activation through three pre-reading activities pictorial context, pre-teaching, and previewing - on reading comprehension of cultural texts among Iranian EFL learners. The results showed that the students' comprehension of cultural texts was improved as a result of the two training sessions of schema activation via the three pre-reading activities. The potential differential effect of each activity per se was not addressed in the study. The two pre-reading activities addressed in the present study are expected to help EFL overcome two major problems that hinders their comprehension: lack of vocabulary knowledge and conceptual knowledge. Limited vocabulary repertoire can lead readers to stop at unfamiliar words that may disrupt comprehension because readers may forget the earlier part of the sentence (Yorio, 1972). [38] This also happens to $\mathrm{L} 1$ readers with decoding problems (Samuels, 1974). [30] Limited vocabulary knowledge also hinders comprehension especially when the meaning of a sentence depends on knowledge of certain words. Vocabulary definitions pre-reading activity may help address these problems. Lack of conceptual knowledge is also common to L1 readers. In a study by Steffensen et al. (1979), college students from India and the United States read letters describing Indian and American weddings. Students read faster and recalled more information when they read the passage about their culture than when they read the passage about the foreign culture. According to Anderson, Reynolds, Schallert, and Goetz (1977) [2] the message intended meaning could be distorted when there is insufficient correspondence between the schemata contained in the text and the one by which the reader assimilates the text. Such distortions can happen particularly when the reader does not share the writer's culture, beliefs, or assumptions. This problem can seriously interfere with EFL readers' comprehension. The pre-reading activity of class discussion may help reduce some of these distortions. To summarize, Theorists in L1 and L2 reading have suggested that providing students with some assistance before reading can help them understand a text. The present study, however, focuses on two specific pre-reading activities: vocabulary definitions and class discussion. Two specific research questions were addressed:

- Do pre-reading activities enhance EFL reading comprehension?

- Does class discussion facilitate EFL reading comprehension better than vocabulary definitions?

\section{Method}

The present study was undertaken because of the evidence of the effectiveness of pre-reading activities in L1/L2 reading and the scarcity of research in this area in EFL reading. The purpose of the study was twofold: first, to determine whether the reading comprehension of EFL Iranian College freshmen 
would be improved when they were exposed to different pre-reading activities (vocabulary definitions and class discussion). Second, by focusing on two types of pre-reading activities, it sought to determine whether one pre-reading activity would facilitate the students' comprehension better than the other. Based on the schema-theoretic view of reading, and on the results of previous empirical studies, it was expected that students' comprehension scores would be higher when the reading was preceded by any of the two pre-reading activities than when reading was not preceded by a pre-reading activity. It was further hypothesized that the students who received the class discussion pre-reading activity would obtain better comprehension scores than those who received the vocabulary definitions activity.

\section{Design}

The design of this study was a random assignment posttest design, wherein participants were randomly assigned to one of three conditions. The schematic representation of this design was as follows (G1 stands for one experimental group, G2 stands for the second experimental group, G3 stands for the control group, $\mathrm{T}$ stands for the experimental treatment, $\mathrm{O}$ stands for the absence of the treatment, and $\mathrm{X}$ stands for the test results.): $\mathrm{G} 1$ (random) $\mathrm{T}_{-} \mathrm{X} \mathrm{G2}$ (random) $\mathrm{T}_{-} \mathrm{X} \mathrm{G3}$ (random) _ $\mathrm{O}_{-} \mathrm{X}$ This design would allow, first, to observe the effects of the treatment the experimental groups received vis-à-vis the control group; second, to compare the comprehension scores of each of the two experimental groups so as to see the differential effect of the two pre-reading activities (vocabulary definitions and class discussion) in facilitating text comprehension.. The independent variable in the present study was the experimental treatment (i.e. the vocabulary definitions and the class discussion pre-reading activities). The dependent variable was the students' comprehension of the text as measured by scores on a comprehension test.

\section{Participants}

Participants in the study were 57 second-semester EFL students selected from more than 800 freshmen attending Qom Islamic Azad University in Iran. This sample is heterogeneous in terms of gender, native language background, and age. The sample comprises males and females who speak either Berber or Iranian as a mother tongue, and whose age ranged between 18 and 27. Besides, they all speak French as a second language in addition to their native language. They were selected and assigned to one of three different groups strictly at random. The effect of the randomization would be to control for all extraneous variables, including ones that the researcher had not even considered. For example, if some of the subjects were proficient skillful readers, they would probably be more or less evenly divided between the treatment and control groups. It does not follow, however, that randomization guarantee that these groups would be identical, but merely that they would tend to be roughly similar on all extraneous variables. More precisely, randomization would ensure that "any differences between the groups were distributed strictly according to the laws of chance" Colman (1995). [12] Therefore, if the groups turned out to differ on the posttest, this difference would have to be either due to the independent variable (the effect of the pre-reading activities) or to chance (Colman, 1995). [12] Another important advantage of randomization is that it provides the option for not using a pre-test as a method of making groups more comparable (Seliger \& Shohamy, 1989).[31] The participants in the study initially totaled 67 students. However, five participants' data were excluded because they were using the dictionary while reading the text, even though they were not allowed recourse to it. Five other participants were eliminated because three of them did not complete the questionnaire, and the remaining two were repeaters.

\section{Materials}

\subsection{The Reading Selection}

The text selected for the study was a 695-word expository passage on "the psychology of migrant workers", a topic of general interest.

The participants themselves confirmed this at the end of the session. In an informal discussion about the treatment, the subjects revealed how interesting and appealing the text was to most of them. Generally, the theme of the text was about the kind of problems migrant workers face in the host country. Furthermore, a number of criteria were considered in the selection of this passage. First, the text type was similar to the texts studied by the students in class. Second, the length of the text was representative of those usually read by second-semester college students. Third, the passage was appropriate in terms of language difficulty. These judgments were made by the participants' actual reading teachers, based on their experience with texts read and studied by their students in class. For this text two pre-reading activities were developed, one activity involved a discussion of the passage content; the second provided definitions and explanations of some difficult key words in the text.

\subsection{The Posttest}

A short-answer test was designed to assess the students' reading comprehension. It included items addressing text explicit and text-implicit information. The test consisted of 7 ( 5 factual and 2 inferential) text-dependent questions and 2 questions dependent on students' background knowledge of the text content. Care was taken to avoid including words or concepts directly discussed in the pre-reading activity to prevent 
the students from answering questions above chance level without having read the passage. A number of considerations were made in the formulation of the short answer questions. Particularly, the factual questions were not directly taken from the text but were paraphrased so as to avoid students matching sentences from the text to provide the correct answer. Also, most of the vocabulary items used in the questions were considered by the students' actual teachers to be familiar to the students. The nine short-answer questions were pilot tested with a group of 10 EFL second-semester students from another Iranian university.

\subsection{The Feedback Questionnaire}

Because of the need for some qualitative feedback to enhance the quantitative data, three versions of the feedback questionnaire were developed and administered by the end of the session to help interpret the data. The questionnaires were developed so that each group involved in the study would complete the appropriate questionnaire based on the treatment they had received. In fact, in addition to eliciting some background information on the participants, the feedback questionnaires also tempted to assess the participants' overall impression about the pre-reading treatment and the control condition. All the questionnaires had three questions in common to which the participants responded either on a two category scale: (yes/no) or on a four-category scale. Each group was asked direct questions about the appropriateness and adequacy of the time limit allotted to reading and to answering comprehension questions. The participants were also asked to rate the text difficulty. This is to know whether the students' performance on the comprehension questions was affected by the text difficulty. For each of the treatment groups, however, three further questions were formulated to probe the facilitative value of the pre-reading activity conducted with each group, and the necessity of having additional activities, as well as the participants' perception of the most effective pre-reading activity. The control group, who received no pre-reading activity, was only asked a question related to the necessity of having some pre-reading activities before a reading task in order to enhance text comprehension. The objective was to obtain feedback on the reading text and reactions to specific aspects of the treatment.

\subsection{Scoring}

The nine short-answer questions were each scored on a three-point scale with a possible maximum total of 18 . Two scoring scales were developed to assign grades to the students' responses to both types of questions: factual and inferential questions. The three-point scale used to score factual questions is shown below:

- $\quad 2$ points $=$ for a complete answer including all explicit text-based information.
- $\quad 1$ point $=$ for an incomplete answer that included only part of the correct text-based information.

- $\quad 0$ point $=$ for an incorrect text-based information or none. The inferential questions were also scored on a three point scale in terms of the appropriateness of the subjects' answers:

- 2 points $=$ for an appropriate and elaborated inferential answer.

- 1 point $=$ for an appropriate inference.

- 0 point $=$ for an inappropriate inference or none. Responses to the short-answer questions were scored by two English teachers, whose scores were combined to produce the final score. In cases of score discrepancies, the raters referred to the researcher in order to decide on the final score to be given. The inter-rater reliability coefficient was estimated to be .94.An internal consistency reliability estimate (K-R 21) of .91 was obtained, indicating that the test items were consistently measuring the same attribute.

\section{Procedure}

This study involved the comparison of three separate groups, with two treatment groups each receiving a different type of pre-reading activity and one control group. Thus, the students were randomly assigned to one of two treatment groups and one control group. There were 19 students in the vocabulary group (12 males and 7 females), 19 students in the discussion group ( 9 males and 10 females), and 19 students in the control group (8 males and 11 females). The three groups were sent to three separate classrooms. Since it was the researcher who was responsible for carrying out the two pre-reading activities, one of the treatment groups had to wait for approximately 20 minutes; that is the time it took to conduct one pre-reading activity with the first group before moving to the second one. An English teacher remained with the first group (the vocabulary definitions group) while the researcher was conducting the discussion activity with the second group. The control group, however, was taken care of by another teacher, since he only provided instructions and directions for the reading task. What was of overriding importance, however, was to have the same person- the researcher- to take care of the two pre-reading treatments in order to decrease the likelihood of mixing between the two pre-reading activities, which could have confounded the results and would have made it difficult to measure the differential effects of each pre-reading activity. Accordingly, each of the treatment groups read the text preceded by a different pre-reading activity, while the control group was directly involved in the reading task with no pre-reading treatment. Thus, in each class there was a person monitoring the students' reading, test taking, and the questionnaire completion. This was to ensure that each group was under the supervision of either the researcher or one of the students' instructors. All the students involved in the study were made 
aware that they were taking part in a research study. The purpose of the research and its procedures were made clear to them at the beginning. The participants had also been told that they would receive a treatment, read a text, take a short comprehension test, and complete a feedback questionnaire at the end. The same information was conveyed to the other treatment group by their teacher supervisor, while waiting for the researcher to finish conducting the vocabulary definitions activity with the first group. The treatment in the present study comprised two different pre-reading activities and a control condition. In the vocabulary definitions condition, the students were provided with explanations of six unfamiliar and key words in the text. The set of words presented in the pre-reading activity were "those which are judged to be outside the learners' current competence and which could otherwise, therefore, pose a comprehending problem"

Widdowson (1978). [37] Accordingly, in the vocabulary definitions pre-reading activity, definitions appropriate e to the six words' used in the text were presented on the board to the students. These vocabulary items were selected by three of the students' English teachers on the basis of (a) the likelihood that they would not be already familiar to the students, and (b) their importance to and necessity for understanding the passage. In the class discussion condition, the students were engaged in a discussion prompted by the following questions: -Why do people migrate in general? -What do you think are the major problems migrant workers face in the host country? These questions were used to elicit what the students know about the topic of the text to be read. On the basis of these general questions, a student-generated discussion took place. The exchange of ideas during this activity was intended to make all the students build a general knowledge of the topic, which would eventually facilitate their reading comprehension. The class discussion was then meant to activate students' prior knowledge about the content area of the reading text, and at the same time provide knowledge some of them may lack. In the control condition, however, the students were first introduced to what they were about to do. They were simply asked to silently read the text, take the test, and complete the questionnaire without being given any specific preparation. The class discussion and the vocabulary pre-reading activities lasted for about 15 min and $7 \mathrm{~min}$, respectively. The students were allowed 20 min to read the text, which was collected immediately afterwards. Students then had $30 \mathrm{~min}$ to complete the test. After that, the tests were collected and Feedback questionnaires were distributed. The completion of the questionnaire took students no more than $5 \mathrm{~min}$. Participants in the control group, however, began reading immediately after receiving the passage and the instructions.

\section{Analysis}

Two types of statistical analyses were conducted on the data collected from the short answer test. First, the scores were submitted to descriptive analysis (X, SD). Second, for inferential analysis, A One-Way Analysis of Variance was run to test for differences among the group scores. Additionally, a post hoc comparison of the group means was performed via the Scheffé contrast test to precisely identify where the significant differences lay. The alpha level of significance was set at a liberal .05. Students' responses to the feedback questionnaires, which were intended for qualitative analyses, were tallied and reported as percentages.

As can be seen from Table 1, an examination of the students' performance on the short-answer test indicates, as expected, that the students who received the pre-reading treatments obtained higher mean scores $(M=9.94 / M=7.68)$ than those who did not $(M=5,94)$.

Table 1. Mean and Standard Deviation on the Short- Answer Test

\begin{tabular}{|c|c|c|}
\hline & N & Mean \\
\hline Discussion Group & 19 & 9.94 \\
\hline Vocabulary Group & 19 & 7.68 \\
\hline Control Group & 19 & 5.94 \\
\hline All students & 57 & \\
\hline
\end{tabular}

The results of the $\mathrm{F}$ test, as can be seen, revealed a significant difference among the means of the three groups on the short-answer test, $\mathrm{F}(2,54)=27.88 ; \mathrm{p}<.05$ This means that the probability is less than $5 \%$ that the observed difference occurred due to chance alone. In other words, one can be $95 \%$ confident that the difference resulted from the treatment the experimental groups received. As the ANOVA procedure revealed significant differences $(\mathrm{p}<.05)$ across the groups, a subsequent analysis was deemed necessary to locate exactly where the differences were; that is, between which of the groups. As a follow-up analysis to the One-Way ANOVA, the scheffé contrast Test was performed to compare for significant differences between pairs of groups. The post hoc comparisons procedure via the Scheffé Test (Table 3) indicated that there were significant differences between each of the treatment groups and the control group, and between the two treatment groups themselves.

The hypotheses tested were that students would attain different comprehension scores with the passage preceded by each of the two different pre-reading activities and that both pre-reading activities would result in higher comprehension scores than the control condition. The comprehension measure was the short-answer test. The descriptive statistics shown in table 1 revealed that there were considerable differences in the mean performances of the treatment groups and the control group. However, the descriptive statistics do not indicate whether the observed differences between groups are significant. A One-Way analysis of variance was computed to see if the differences observed among the means of the three groups were significant. Results of the analysis of variance on the short-answer test are shown in Table 2. 
Table 2. ANOVA for Differences among Control and Treatment Score on the Short-Answer Test

\begin{tabular}{|c|c|c|c|c|}
\hline Source of Variance & SS & DF & MS & F \\
\hline Between Groups & 152.856 & 2 & 76,428 & \\
\hline Within Groups & 147.025 & 54 & 2,741 & $27.88^{*}$ \\
\hline Total & 300.881 & 56 & & \\
\hline
\end{tabular}

$* \mathrm{P}<.05$

As shown in Table 3, post-hoc comparisons (Scheffé Test) revealed significant differences across the three groups. The class discussion treatment group obtained significantly $(p<.05)$ higher scores than the control group. The vocabulary definitions group performed significantly better than the control group $(\mathrm{p}<.05)$. Moreover, the follow-up analysis also revealed a significant difference between the two treatment groups $(\mathrm{p}<.05)$. The class discussion group thus significantly outperformed the vocabulary definitions group on the short-answer test. Clearly, the mean score, the F-test, and post-comparisons provide ample evidence that the pre-reading treatment made the differences between each of the two treatment groups and the control group.

Table 3. Scheffe Test of Differences across Groups

\begin{tabular}{|c|c|c|c|}
\hline Group & Group 1 & Group 2 & Group 3 \\
\hline 1 & & $2.26^{*}$ & $4.00^{*}$ \\
\hline 2 & & & $1.73^{*}$ \\
\hline
\end{tabular}

$* \mathrm{P}<.05$

Note: G1=class discussion, G2=vocabulary definition, G3=Control

\section{Discussion}

The first basic question in this study was whether or not pre-reading activities enhance EFL reading comprehension. The results are straightforward and make a strong argument in favor of using pre-reading activities with Iranian college freshmen. Specifically, the class discussion pre-reading activity and exposure to definitions of difficult words in the text prior to reading seem to have resulted in better comprehension of the expository text used in the present study reading research in L1 and L2 fields has shown that pre-reading activities can enhance students' reading comprehension (Bransford \& Johnson, 1972; Davis, 1994; Floyd \& Carrell, 1987; Johnson, 1982; Graves et al., 1980, 1981, 1983, 1995; Hudson, 1982, Langer, 1984; Maghsoudi, 2012; Stevens, 1982). [5] The results of this study clearly indicate that, similarly to L1 reading context, pre-reading activities can be successfully applied to an EFL context. The major findings of this study provide support for the facilitative effects of pre-reading activities for EFL College students. The students' responses to the feedback questionnaire provided further support for the importance of pre-reading activities in enhancing comprehension. Analysis of the class discussion and vocabulary groups' responses to the feedback questionnaire indicated that the majority of the students in each of these groups expressed positive feeling about the treatment they received. The majority of participants reported that the pre-reading activities they received helped them understand the meaning of the text better.

The second research question was - Does class discussion facilitate EFL reading comprehension better than vocabulary definitions?-. The obtained results suggest an affirmative answer. In effect, it was found that the class discussion pre-reading activity facilitated students' comprehension of the expository text more than the other activity in which students were presented with vocabulary definitions. This indicates that the vocabulary definitions pre-reading activity did not seem to have been as effective as the class discussion in facilitating students' comprehension of the text.

The results suggest that different pre-reading activities can have a differential facilitative effect upon EFL students' comprehension.

Yet, it can be argued that the results of the present study might have been produced by other uncontrolled variables. For example, it might be that the class discussion group and/or the vocabulary group already included students with good reading skills and strategies, and that this was the reason behind their out-performance over the control group. However, the effect of this variable, which might be inherent in the students, was in effect minimized by the random assignment of the students to groups. This constitutes a counter-argument against the probability that the students might not have been equivalent at the outset in terms of their reading proficiency.

The obtained results could have been affected by the text difficulty. However, looking at the participants' answers on the feedback questionnaire, the probability to attribute the results to the difficulty of the text seems to be very low. None of the students rated the text as being ,,very difficult'. Thus, answers yielded by the control group showed that, only $5.26 \%$ of the students rated the text as being ,difficult', Similarly, $5.26 \%$ of the students in the vocabulary group rated the text as being 'difficult'. In the discussion group, $15.78 \%$ of the students rated the text as 'difficult' as can be seen, none of the three groups found the text too difficult. These results lower the probability that the control group performance on the comprehension test was negatively affected by the text difficulty and that the out-performance of both the class discussion and the vocabulary groups was not the result of the pre-reading treatment they received.

Another variable, likely to influence the subjects' performance on the comprehension test, is the time allotted to reading and to test taking. However, it seems that the impact of time is not as clear as the impact of text difficulty.

In fact, analysis of the class discussion, vocabulary definitions, and control groups' responses on the feedback questionnaires indicated that these groups did not agree about the adequacy of the time assigned to reading and test-taking. A possible explanation is that the treatment each group received might have been responsible for the students' 
view of time sufficiency for reading and test taking. For the class discussion group, it could be that the discussion, by providing new background knowledge or by activating pre-existing knowledge, assisted students to quickly construct the meaning of the text in the specified time. For the vocabulary definitions group, it might be that the emphasis on vocabulary items in the pre-reading phase had led students to work through the text on a rigid, word-by-word fashion. This might also be the case with students in the control group who received no pre-reading assistance. Since the reading selection proved to include words that were unfamiliar to all students in each of the three groups, this might result in having the students in the control group grapple with each difficult word they came across in the text.

Investigation of the differential potential of pre-reading activities on students' comprehension of the text indicated that EFL reading comprehension of Iranian second-semester college students was more significantly facilitated when reading was preceded by a discussion of the text topic than when reading was preceded by explanation of unfamiliar words to be encountered in the text. In this respect, Gebhard (1987) asserted that "short class discussions before students read can be directed at activating students' existing knowledge and increasing sensitivity to the content of the reading material" (p. 23). Class discussions do not only provide an opportunity for students to consider their own experience in relation to the topic of reading, but will also help students "to develop a context in which to read and to develop expectations about what they will find" (Silberstein, 1994, p. 43). [32] Furthermore, students will feel free to voice out their opinions without constraints.

This finding is noteworthy because it runs parallel to some empirical evidence in favor of the differential effect of pre-reading activities on reading comprehension (Hudson, 1982; Johnson, 1982; Langer, 1984; Taglieber, Johnson \& Yarbrough, 1988; Webb, 2009). [25] This is in accordance with the schema-theoretic view of reading which holds that comprehension depends on readers' background knowledge of the topic of a given text. Thus, if these readers are faced with highly unfamiliar content, especially materials with many culturally loaded concepts, comprehension will be difficult, if not impossible, due to the readers' lack of appropriate background knowledge.

Particularly, the studies incorporating vocabulary definitions as a pre-reading activity (Hudson, 1982; Taglieber et al, 1988) yielded similar results to those obtained in the present study. In fact, even though Hudson's vocabulary activity included a prediction component, it did not surpass performance of those who did a read-test/reread-retest activity or a pictorial prediction activity. Furthermore, Taglieber et al. (1988) explains that the poor performance of the vocabulary group might be due to the fact that the words were not related to the content of the reading selections. In contrast, the definitions of words presented in the pre-reading activity examined in the present study were those appropriate to their use in the reading text. Nonetheless, it seems to be no better than Taglieber et al.'s pre-teaching vocabulary activity.

One possible interpretation of such findings is that although knowledge of these words meanings was essential for adequate comprehension to occur, heightened background knowledge from the class discussion pre-reading activity made students more able to use context to arrive at a satisfactory meaning of the text even if they are not familiar with certain words in the text. [33] (1980), in his discussion of his interactive compensatory model of reading, cites evidence to support the view that contextual information may help readers compensate for poor word recognition.

A second possible interpretation of the finding that vocabulary definitions was less effective than the class discussion may be the inadequacy of the set of words explained in the pre-reading activity. It is possible that the six items presented before reading were not the only unfamiliar words likely to cause difficulty for students to understand the text. In fact, analysis of the vocabulary group responses to the feedback questionnaire showed that $57.89 \%$ of the students thought that there were some other words in the text that needed to be explained. More importantly, the emphasis on vocabulary words for this group may have encouraged word-by-word reading, which may consequently have prevented students from using their background knowledge and context to predict the meaning of unfamiliar words and of the text in general, even though they performed better than the control group.

A third possible interpretation may be found in students' reactions to each of the two pre-reading treatments. The class discussion appeared to produce higher motivation and a more active involvement of the students in the activity. On the other hand, vocabulary definitions did not seem to be as appealing to students, most probably because it is a familiar technique to them, and also because it did not lend itself to much involvement on their part.

Such findings seem to back up Carrell's (1984) conclusion that "simply teaching lists of words or even words in context is not going to help students relate the new concepts to their old knowledge and to integrate the new words into their vocabularies" (p. 340). Although in the present study, the definitions of words presented prior to reading referred to the meanings intended by the context in which they occurred in the text, they seem not to have improved students comprehension as effectively as the class discussion. In this regard, Hudson (1982) holds that even when words taught in a pre-reading activity are evocative of the content of a passage and may help students make predictions about it, there is no guarantee that this will surpass direct knowledge of the task at hand. In light of this, the vocabulary definitions activity, employed in the present study, could have been more effective if it had included a background knowledge component (Maghsoudi, 2012). [26] In fact, Carrell (1984, 1988) proposed that instead of pre-teaching vocabulary for single reading passages, teachers should be pre-teaching 
vocabulary and background knowledge concurrently. Similarly, Beck et al. (1982) and Stevens (1982) [3] both suggested that words should be taught in semantically and topically related sets so that word meaning and background knowledge develop concurrently.

In contrast to the vocabulary definitions, the class discussion seemed to have had a more facilitating effect on students' comprehension of the text. A plausible explanation is that the information generated by the class discussion may have helped students either create or activate schemata that helped them understand the text. Thus, the discussion was beneficial both to students who already had some knowledge about the topic, in that it raised their awareness of such knowledge, and to students who had no prior knowledge, in that it helped them build awareness of new concepts. In both cases, class discussion seemed to have aroused subjects' interest and motivation through linking the topic of the text to their existing background knowledge.

The present study supports Hudson's (1982) [21] and Hammadou's (1991) contention that students may use their background knowledge about a reading selection to override problems they are having with the language. In effect, though $73.68 \%$ of the students in the class discussion group declared on the feedback questionnaire that there were some key words in the text that should have been explained prior to reading, their comprehension of the text seemed to have been facilitated by the class discussion.

The success of the class discussion condition in the present study adds weight to Carrell's (1984) contention that for a pre-reading activity to be effective, it has to accomplish two main goals: providing background knowledge as well as evoking pre-existing knowledge. It also supports the view of schema theory asserting that activating or building readers' background knowledge prior to reading would improve reading comprehension. In this view, reading is the result of a two-way communication between the reader and the text, achieved through simultaneous interaction of bottom-up information processing and top-down processing. Meaning does not just reside in the text; it is rather constructed out of the interaction between the reader's background knowledge and the text itself. The construction of meaning suffers if a reader does not make effective use of his/her background knowledge base.

\section{Pedagogical Implications}

The results of this study have definite implications for EFL reading teachers. They seem to provide evidence in support of pre-reading activities as useful techniques for facilitating EFL reading comprehension. These findings suggest that EFL teachers should be aware of the beneficial effects of pre-reading activities in facilitating students' reading comprehension. Because class discussion and vocabulary definitions are relatively easy to prepare and take little time to present, teachers should be encouraged to use these kinds of pre-reading activities to assist students in reading. Teachers may want to use one of the two pre-reading activities (vocabulary definitions, or class discussion) depending on the students' needs and the characteristics of the text, or they may want to combine the two activities with the same text. In fact, $43.85 \%$ of the students, as indicated in the feedback questionnaires, believed that a combination of the two activities would be more efficient in improving their understanding of the text. Carrell (1984) argues that "if teaching new vocabulary is to be effective, it must be integrated with both the students pre-existing knowledge and other pre-reading activities designed to build background knowledge."

It does not follow, however, that the two pre-reading activities should be used all the time. Teachers should select teaching techniques to fit particular situations. Whether to use vocabulary definitions, class discussion, or give some other kinds of pre-reading assistance in a particular situation depends on the selection to be read, the students who will read it and the purposes of their reading it. Teachers need to take into account the needs of their students, the specific objectives the reading lesson aims to achieve, as well as the materials used for reading in order to construct appropriate pre-reading activities.

Furthermore, as indicated in the participants' responses to the feedback questionnaire, students need assistance with difficult words. Because English vocabulary is very likely to pose problems for many EFL learners (Carrell, 1984; Grabe, 1991), [16] it seems quite reasonable to include vocabulary definitions within any pre-reading activity. This should be very facilitative, especially for difficult reading selections.

Pre-reading activities are also motivational devices. According to the feedback questionnaire, all the participants in the treatment groups said that they appreciated and found it helpful to do pre-reading activities before reading the passage. Students from the control group suggested that pre-reading activities be used more frequently in their actual EFL reading classes. Activities of the type used in this study, especially the class discussion, might not only increase students' comprehension of the passage they read, but might also make reading more enjoyable and thus encourage more extensive reading, which would result in the building of background knowledge and lead to a better grasp of the English language. In this regard a number of researchers have underlined the importance of extensive reading in building background knowledge and promoting vocabulary acquisition (Krashen, 1989; Nation \& Coady, 1988 in Paribakht \& Wesche, 1997). [24]

\section{Limitations and Concluding Remarks}

In educational research no study is devoid of certain limitations, and thus any interpretation of the results should be done cautiously and with certain limitations in mind. 
The first limitation of this study concerns the limited size of the sample. 57 second-semester college students from a population of more than 800 has, in fact, impeded the generalizability of the findings to cover the wider population of EFL Iranian college freshmen. The second limitation has to do with the use of one reading selection. In fact, the findings of this study could have been more suggestive if more than one text was used. In this way, the probability that the obtained results were due to a single passage effect could have been reduced. Perhaps, the third limitation of this study concerns the use of a single testing method (short-answer questions) to assess students' comprehension of the text. Other types of data collection could have been used in order to gain a well-rounded picture of how well students did comprehend the text. Finally, the results of this study only concern the use of two pre-reading activities (class discussion and vocabulary definitions) and do not speak to all pre-reading activities in general.

In addition to this, several other issues have emerged which deserve further attention and research. While this study has laid the ground for using pre-reading activities, namely class discussion and vocabulary definitions, to enhance students' reading comprehension, future studies of pre-reading activities might also be designed to address other issues not accounted for in this study. First, future research needs to determine the impact of pre-reading activities on students' comprehension of different kinds of textual information such as the differential potential of certain types of pre-reading activities on students' comprehension of explicit and implicit information. Second, future studies need to address the extent to which different kinds of passages benefit from different kinds of pre-reading activities. For example, highly concrete passages might benefit equally well from vocabulary definitions and class discussion, whereas more abstract passages might be better addressed by other pre-reading activities. Finally, further research needs to be carried out to help establish if a combination of the two pre-reading activities addressed in this study will be more beneficial for the language learner.

Another aspect not touched upon in the study, and which is worth of attention, is the effect of pre-reading activities on reading comprehension of students at various levels of language proficiency. The main issue here would concern the possible interaction of the different proficiency levels with a particular pre-reading treatment. Another issue worth-investigating is the way pre-reading activities are conducted. For example, the activities conducted in this study can be manipulated to alter the power of their effects (e.g., the class discussion could also be prompted by pictures). Thus, studies might be undertaken to refine the structure of pre-reading activities and to test the effect of the possible ways of conducting them with different text types.

Last but not least, although pre-reading activities, especially those that provide background knowledge, assist students increasing text comprehension, these activities are under the teacher's control rather than the students'. Because of this, it remains unclear whether students' comprehension with the teacher's support will help them develop useful strategies to handle their independent reading outside class more successfully, making a more effective use of their background knowledge. Thus, further studies would need to investigate the impact of such techniques on students' independent reading.

To sum up, despite the limitations stated above, the results of this study suggest that the use of pre-reading activities can significantly aid EFL reading comprehension. EFL teachers can be well served by adaptive use of pre-reading activities. Teachers can try the various activities and develop their personal knowledge about what works and what does not work for them with different texts and reading purposes.

\section{REFERENCES}

[1] Anderson, R. C., \& Pearson, P. D. (1984). A Schema-Theoretic View of Basic Processes in Reading Comprehension. In P. D. Pearson (Ed.), Handbook of reading research (pp. 37-55). New York: Longman.

[2] R. C., Reynolds, R. E., Schallert, D. L., \& Goetz, E. T. (1977). Frameworks for Comprehending Discourse. American Educational Research Journal, 14, 367-381.

[3] Beck, I. L., Perfetti, C. A., \&McKeown, M. G. (1982). Effects of Long-Term Vocabulary Instruction on Lexical Access and Reading Comprehension. Journal of Educational Psychology, 74, 506-21.

[4] Bernhardt, E, B. (1984). Towards an Information Processing Perspective in Foreign Language Reading. Modern Language Journal, 68, 322-331

[5] Bransford, J. D., \& Johnson, M. K. (1972). Contextual Prerequisites for Understanding: some Investigations of Comprehension and Recall. Journal of Verbal Learning and Verbal Behavior, 11, 717-726.

[6] Carlo, M., August, D., McLaughlin, B., Snow, C., Dressler, C., Lippman, D., Lively, T. J., \& White, C. E. (2004). Closing the gap: Addressing the Vocabulary Needs of English-Language Learners in Bilingual and Mainstream Classrooms. Reading Research Quarterly, 39,188-215.

[7] Carrell, P. L. (1983). Three Components of Background Knowledge in Reading Comprehension. Language Learning, 33, 183-207.

[8] Carrell, P.L. (1984). Schema Theory and ESL Reading: Classroom Implications and Applications. The Modern Language Journal,68, 332-343

[9] Carrell, P. L. (1988). Interactive Text Processing: Implications for ESL/Second Language Reading Classroom. In P. L. Carrell, J. Devine, \& D. Eskey (Eds.), Interactive approaches to second language reading (pp.239-259). New York: Cambridge University Press.

[10] Carrell, P. L., \& Eisterhold, J. C. (1983). Schema Theory and ESL Reading Pedagogy. TESOL Quarterly, 17, 553-573. 
[11] Carrell, P.L., \& Wallace, B. (1983). Background Knowledge: Context and Familiarity in Reading Comprehension. In M. A Clarke \& J. Handscombe (Eds.), On TESOL' 82 (pp. 295308). Washington, DC: TESOL.

[12] Colman, A. M. (1995). Introduction. In A. M. Colman (ed.), Psychological Research Methods and Statistics (pp. xi-xvi). London and New York: Longman.

[13] Davis, Z. T. (1994). Effects of pre-reading story mapping on elementary readers' comprehension. Journal of Educational Research, 87, 353-360.

[14] Floyd, P., \&Carrell, P. L. (1987). Effects on ESL Reading of Teaching Cultural Content Schemata. Language Learning, 37, 89-109.

[15] Gebhard, J. G. (1987). Successful Comprehension: What Teachers Can Do Before Students Read. English Teaching Forum, 25(4), 21-23.

[16] Grabe, W. (1991). Current Development in Second Language Reading Research. TESOL Quarterly, 25, 375-406.

[17] Graves, M. F., \& Chen, H. (1995). Effects of Previewing and Providing Background Knowledge on Taiwanese College Students' Comprehension of American Short Stories. TESOL Quarterly, 29, 663-686.

[18] Graves, M. F., \& Cooke, C. L. (1980). Effects of Previewing Difficult Short Stories for High School Students. Research Graves, M. F., Cooke, C. L., \& LaBerge, M. J. (1983). Effects of previewing Difficult Short Stories on Low Ability Junior High School Students' Comprehension, Recall, and Attitude. Reading Research Quarterly, 18, 262-276.

[19] Graves, M. F., \& Palmer, R. J. (1981). Validating Previewing as a Method of Improving Fifth and Sixth Grade Students' Comprehension of Short Stories. Michigan Reading Journal, $15,1-3$

[20] Hammadou, J. A. (1991). Interrelationships among Prior Knowledge Inference and Language Proficiency in Foreign Language Reading. Modern Language Journal, 75, 27-38.

[21] Hudson,T. (1982). The Effects of Induced Schemata on the "Short-Circuit" in L2 Reading: Non-Decoding Factors in L2 Reading Performance. Language Learning, 32, 1-31.

[22] Johnson, P. (1981). Effects on Reading Comprehension of Language Complexity and Cultural Background of a Text. TESOL Quarterly, 15, 169-181.

[23] Johnson, P. (1982). Effects on Reading Comprehension of Building Background Knowledge. TESOL Quarterly, 16, 503-516.

[24] Krashen, S. D. (1989). We Acquire Vocabulary and Spelling by Reading: Additional Evidence for the Input Hypothesis.
Modern Language Journal, 73, 440-464.

[25] Langer, A. J. (1984). Examining Background Knowledge and Text Comprehension. Reading Research Quarterly, xix, 468-481.

[26] Maghsoudi, N. (2012). The Impact of Schema Activation on Reading Comprehension of Cultural Texts among Iranian EFL Learners. Canadian Social Science, 8(5), 196-201.

[27] Nation, I. S. P., \& Coady, J. (1988). Vocabulary and Reading. In R. Carter \& M. McCarthy (Eds.), Vocabulary and Language teaching (pp. 97-110). New York: Longman.

[28] Paribakht, T. S., \& Wesche, M. (1997). Vocabulary Enhancement Activities and Reading for Meaning in Language Vocabulary Acquisition. In J. Coady \& T. Huckin (Eds.), Second language vocabulary acquisition (pp.174-200). Cambridge: Cambridge University Press.

[29] Rumelhart, D. E. (1980). Schemata: the Building Blocks of Cognition. In R. Spiro, B. Bruce \& W. Brewer (Eds.) Theoretical issues in reading comprehension (pp. 33-58). Hillsdale, NJ: Erlbaum.

[30] Samuels, S. J. (1977). Introduction to Theoretical Models of Reading. In w. Otto, C. W. Peters, \& N. Peters (Eds.), Reading problems: A multidisciplinary perspective (pp.7-41). Reading, MA: Addison-Wesely.

[31] Seliger, H. W., \&Shohamy, E. (1989). Second language research methods. Oxford: Oxford University Press.

[32] Silberstein, S. (1994). Techniques and resources in teaching reading. Oxford: Oxford University Press.

[33] Stanovich, K. E. (1980). Toward an Interactive-Compensatory Model of Individual Differences in the Development of Reading Fluency. Reading Research Quarterly, 16, 32-71.Steffensen, M, S., Joag-dev, C., \& Anderson, R, C. (1979). A cross-Cultural Perspective on Reading Comprehension. Reading Research Quarterly, 15, 10-29.

[34] Stevens, K. (1982). Can we Improve Reading by Teaching Background Information? Journal of Reading, 25, 326-329.

[35] Taglieber, L. K., Johnson, L. L., \& Yarbrough, D. B. (1988). Effects of Pre-Reading Activities on EFL Reading by Brazilian College Students. TESOL Quarterly, 22, 455-472.

[36] Webb, S.A. (2009). The Effects of Pre-Learning Vocabulary on Reading Comprehension and Writing. The Canadian Modern Language Review, 65, 3, 441-470.

[37] Widdowson, H. G. (1978). Teaching language as communication. Oxford: Oxford University Press.

[38] Yorio, C. A. (1972). Some Sources of Reading Problems for Foreign Language Learners. Language Learning, 21, 107-115. 